\title{
A simplified method for lignin measurement in a range of forage species
}

\author{
A.V. CHAVES ${ }^{1,2}$, G.C. WAGHORN ${ }^{1}$ and M.H. TAVENDALE ${ }^{1}$ \\ ${ }^{1}$ AgResearch Grasslands, Private Bag 11008, Palmerston North \\ ${ }^{2}$ Massey University, Palmerston North, New Zealand \\ alexandre.chaves@agresearch.co.nz
}

\begin{abstract}
Lignin is the prime factor influencing the digestibility of plant cell wall material. As concentrations of lignin increase, digestibility, intake and animal performance usually decreases. Presented is a simplified acid detergent lignin procedure which has been used to determine lignin concentration from a wide range of forages and also ryegrass at different stages of maturation. Forages used in this study included grasses, legumes, herbs and conserved material, with lignin concentration ranging from 2.02 to $21.1 \%$ of the DM. Legumes tended to have higher values than grasses, and ryegrass maturation was not accompanied by increased lignin concentration at 53 days of age. These results will be incorporated into a NIRS method for determining forage quality, and used in a dairy nutrition model to assist in ration formulation for dairy cows.
\end{abstract}

Keywords: analytical method, fibre, forages, lignin

\section{Introduction}

\section{Importance of lignin for ruminants}

Lignin is a major anti-nutritional component of grasses. Lignin limits cell wall (fibre) digestion by providing a physical barrier to microbial attack and the concentration of both fibre and lignin increases as plants mature (Van Soest 1978; Chaves et al. 2002). Ruminants can digest the cellulose and hemicellulose components of fibre but the lignin inhibits the rate and extent of digestion especially when the proportion of lignin in fibre begins to increase. Lignin precursors also have anti-microbial properties (Jung \& Fahey 1983). However it benefits plants by providing mechanical support, water impermeability and protection from insects.

Abundant data show negative correlations between the lignin concentration in plants and both dry matter (DM) and fibre digestibility (Jung et al. 1997). Lignin is more prevalent in grass stem than leaf and absent from legume leaves. In contrast to grasses, there are minimal ferulate cross linkages between lignin and hemicellulose in legume stems (Hatfield et al. 1999), so the lignin concentration is less detrimental to nutritive value of legumes, compared to grasses. This was demonstrated by more rapid degradation of legume fibre than grass fibre (Jung et al. 1997).

A good understanding of fibre, its composition, degradation and effects on energy availability is essential for maintaining a nutrient supply to high producing animals. The rate of digestion, breakdown by chewing and clearance from the rumen determine feed intake, and rumen capacity is likely to limit future increases in productivity from ryegrass based pasture (Waghorn 2002). Flowering is associated with significant reductions in intake.

There are several chemical classifications of fibre, usually based on sequential removal of constituents by boiling in detergents or acids. Plant residues remaining after boiling in neutral detergent are not available for ruminant absorption unless they are degraded by microbial fermentation. The neutral detergent fibre (NDF; the residue after boiling in a neutral detergent) comprises hemicellulose, cellulose, lignin and ash, commonly referred to as the cell wall or fibre fraction of plants. Digestion of NDF in an acid detergent removes hemicellulose leaving the acid detergent fibre (ADF) fraction, and a further digestion in $12 \mathrm{M}$ sulphuric acid removes cellulose leaving lignin and ash. Lignin is determined after the mineral (ash) fraction is measured by ashing.

Measuring lignin is complicated by the extensive cross linkages with cellulose and hemicellulose and the insolubility of this polymer (Hatfield et al. 1994). A variety of methods have been developed to estimate lignin with the acid detergent lignin (ADL) procedure (Van Soest 1967) usually employed for forage analysis.

This paper presents a method, which was adapted from Goering \& Van Soest (1970) to simplify lignin measurements, together with data from a wide range of forages and also ryegrass of increasing maturity. These data will be incorporated into a NIRS (Near Infra Red Spectrometer) method for determining forage quality, enabling improved predictions of animal performance and formulation of mixed forage rations for dairy cows to avoid current limitations of rumen fill.

\section{Methods}

\section{Measurement procedure}

Lignin is usually determined as part of a sequential extraction comprising three refluxing and filtering steps; firstly with neutral detergent, followed by acid detergent and lastly $12 \mathrm{M} \mathrm{H}_{2} \mathrm{SO}_{4}$ digestion to leave lignin and ash residues. The standard ADL determination uses about $1 \mathrm{~g}$ dried material, requires condensing and refluxing apparatus including $600 \mathrm{ml}$ Berzelius beakers for boiling and $50 \mathrm{ml}$ fritted glass crucibles (coarse porosity) to 
retain residues after refluxing. The main modifications of the ADL procedure of Goering \& Van Soest (1970), presented here, are the removal of the the neutral detergent fibre step and a reduction in the quantity of material required for analysis. Screw capped culture tubes $(16 \times 100 \mathrm{~mm})$ have been used for digestion in both acid detergent and $12 \mathrm{M} \mathrm{H}_{2} \mathrm{SO}_{4}$ to obtain an acid-insoluble residue lignin and ash residue. Glass microfibre filters (Whatman $55 \mathrm{~mm}$ GF/C) were used for collecting fibre residues from the digestion tubes after the final digestion and for ashing. The modified technique is presented in Table 1.

This technique was tested to determine variability and precision and used to determine lignin concentration in a wide range of forage samples.

\section{Repeatability}

Replicate analysis is the primary means of evaluating data variability or precision. The coefficient of variation $(\mathrm{CV})$ was used as a measure of repeatability:

$\mathrm{CV}(\%)=(\mathrm{SD} / \mu) \times 100$

Where $\mathrm{SD}=$ sample standard deviation and $\mu=$ mean of replicate analyses.

Precision was monitored by a reference standard (ryegrass/white clover pasture) analyzed with every batch of 20 forage samples. Standard deviation (SD) was calculated from repeated analysis of control samples and duplicates of the forage samples.

The modified ADL method has been used to determine the lignin concentration of a range of forage types and also ryegrass of increasing ( 21 to 105 days) maturity. These data were required for model prediction of forage mixed rations for high producing dairy cows.

\section{Results}

The technique developed for lignin measurements (Table 1) resulted in good repeatability for a wide range of forage types (Table 2). In most cases the CV was less than 5\%. It is however important to be aware that the condensed tannins present in some forages have been shown in this laboratory to comprise part of the lignin fraction after acid digestion. True lignin will be calculated from $12 \mathrm{M}$ sulphuric acid residue less the values for ash and tannins determined by a separate analysis.

The forages used for the lignin assay (Table 2) are used in farming systems and were part of a systematic study of feeding values by Burke et al. (2000) and Chaves et al. (2001). All grasses except those in the "maturation" trial were leafy and vegetative, and had similar concentrations of lignin (about 3\% of DM) except for cocksfoot and paspalum. Lignin concentration in clover and lucerne were higher than most of the grasses, but the values for Lotus species were elevated by the presence of tannins. Most surprising were the high values for
Table 1 Modified procedures for the determination of acid detergent lignin (ADL).

(Procedure to obtain acid detergent fibre (ADF) for ADL analysis)

1. Dry $16 \mathrm{ml}$ glass tubes at $100^{\circ} \mathrm{C}$ for at least an hour.

1. Weigh tubes to 4 or 5 decimal places in groups of 10 at a time ${ }^{1}$.

2. Dry finely ground samples at $60{ }^{\circ} \mathrm{C}$ and weigh about $250 \mathrm{mg}$ into weighed tubes. (G rinding was carried out in a Wiley mill with a $1 \mathrm{~mm}$ screen (Mertens 1992)).

3. Add $10 \mathrm{ml}$ acid detergent fibre solution ( $2 \%$ cetyl trimethylammonium bromide in 1 litre $0.5 \mathrm{M} \mathrm{H}_{2} \mathrm{SO}_{4}$ ) to the sample. Put cap on tube. Vortex.

4. Reflux over a steady heat (water bath) for one hour at $95-100{ }^{\circ} \mathrm{C}$, vortex every 10 minutes.

5. Centrifuge for 10 minutes at $3000 \mathrm{rpm}$ and remove supernatant by suction.

6. Add $15 \mathrm{ml}$ hot distilled water to residue; vortex. Centrifuge for 10 minutes at $3000 \mathrm{rpm}$ and discard supernatant. Repeat this step 3 times.

7. Add $15 \mathrm{ml}$ acetone to the residue; Vortex. Centrifuge for 10 minutes at $3000 \mathrm{rpm}$ and discard supernatant. Repeat this step 1 more time.

8. Evaporate residual acetone in water bath at $60^{\circ} \mathrm{C}$.

9. Dry tubes at $90{ }^{\circ} \mathrm{C}$ overnight.

10. Weigh tubes and residue using hot weighing technique to 4 or 5 decimal places, calculate ADF (Mertens 1992).

(ADL procedure)

A protective mask MUST be worn when handling $12 \mathrm{M} \mathrm{H}_{2} \mathrm{SO}_{4}$ in this assay.

11. Label glass microfibre filters (GMF) with marker pen (both sides), dry at $100{ }^{\circ} \mathrm{C}$ over night and weigh 10 tubes at a time ${ }^{1}$ to 5 decimal places.

12. Add $1.5 \mathrm{ml} 12 \mathrm{M} \mathrm{H}_{2} \mathrm{SO}_{4}$ to tubes containing residues (in fume cupboard) and digest at $30{ }^{\circ} \mathrm{C}$ for 60 minutes mixing carefully every 10 minutes.

13. Following digestion the acid-insoluble residue was collected by filtration using $45 \mathrm{~mm}$ Buchner funnels with pre-weighed $55 \mathrm{~mm}$ Whatman GF/C glass microfibre filters. An extensive washing with water and a final acetone rinse (twice) was used prior to drying the samples overnight at $100{ }^{\circ} \mathrm{C}$.

14. Weigh the filters and residue to 5 decimal places.

15. Ash at $450{ }^{\circ} \mathrm{C}$ for 6 hours. Weigh GMF with ash to 5 decimal places.

16. ADL was determined as the difference in weight of the residue before and after ashing, with correction for ashing losses from GMF².

${ }^{1}$ When 24 tubes (or GMF) were removed from $105^{\circ} \mathrm{C}$ in a single batch, weight of first tube did not change over the time the 24th tube were weighed ( $\sim 5$ minutes) so can remove more than 10 at once.

2 Include 8 additional GMF blanks with each batch of 22 forage samples to determine ashing losses from GMF.

lignin in chicory and plantain, both of which have very low fibre concentrations (Burke et al. 2000).

The concentration of lignin in ryegrass increased as 
Table 2 Comparative ADL concentration (\% of DM) of different feeds.

\begin{tabular}{lrr}
\hline Feed & ADL ${ }^{1} \%$ & CV $\%$ \\
\hline Fresh grasses & & \\
Lolium perenne & & \\
$\quad$ (Perennial ryegrass AR $1^{2}$ ) & 2.92 & 1.14 \\
Holcus lanatus (Yorkshire fog) & 3.13 & 2.20 \\
Lolium perenne & & \\
$\quad$ (Perennial ryegrass Nil Endophyte) & 3.38 & 2.23 \\
Bromus willdenowii (Prairie grass) & 3.78 & 0.92 \\
Festuca arundinacea (Tall fescue) & 3.78 & 2.97 \\
Pennisetum Clandestinum (Kikuyu) & 3.82 & 2.05 \\
Dactylis glomerata (Cocksfoot) & 5.13 & 2.72 \\
Paspalum dilatatum (Paspalum) & 6.85 & 2.52 \\
Legumes and herbs & & \\
Trifolium repens (White clover) & 5.87 & 2.04 \\
Medicago sativa (Lucerne) & 6.12 & 3.34 \\
Trifolium pratense (Red Clover) & 6.23 & 12.53 \\
Cichorium intybus (Chicory) & 6.97 & 6.96 \\
Lotus corniculatus (Birdsfoot trefoil) & $7.22^{3}$ & 4.40 \\
Lotus pedunculatus (Lotus major) & 16.973 & 3.48 \\
Plantago lanceolata (Plantain) & 21.10 & 0.72 \\
Conserved & & \\
Zea maize (Maize grain) & 2.02 & 2.72 \\
Avena sativa (Oat silage) & 4.29 & 4.03 \\
Lolium perenne & & \\
$\quad$ (Perennial ryegrass silage) & 4.31 & 4.56 \\
Zea maize (Maize silage) & 4.36 & 3.87 \\
Zea maize (Maize silage) & 4.95 & 1.31 \\
Medicago sativa (Lucerne silage) & 7.33 & 0.06 \\
Medicago sativa (Lucerne hay) & 8.04 & 0.40 \\
Perennial ryegrass maturation & & \\
Perennial ryegrass 21 days & 2.65 & 4.54 \\
Perennial ryegrass 31 days & 2.38 & 5.94 \\
Perennial ryegrass 53 days & 2.51 & 3.10 \\
Perennial ryegrass 74 days & 2.63 & 0.27 \\
Perennial ryegrass 88 days & 3.02 & \\
Perennial ryegrass 105 days & 4.35 & \\
Pasture reference standard & 5.34 & 3.78 \\
Pasture reference standard & 5.78 & 2.33 \\
\hline 1 Mean of values. & & \\
2 AR1, AgResearch cultivar with endophyte (Neotyphodium lolii) \\
$\quad$ selection for high in peramine butlow in other key alkaloids. \\
3 Lignin includes condensed tannins. & & \\
\hline & & \\
\hline
\end{tabular}

the grass aged and was strongly correlated with the decline in organic matter digestibility (Figure 1A; $\left.\mathrm{r}^{2}=0.90\right)$. Lignin and NDF concentration increased simultaneously, but the relative rate of change showed lignin increased more rapidly than NDF (Figure 1B). Mature ryegrass was digested much more slowly by rumen microflora after mincing (in sacco) than young ryegrass (Figure 1C; Chaves et al. 2002).

\section{Discussion}

The data presented here show that a rapid lignin assay, based on fewer steps and smaller quantities of samples and reagents (compared to Goering \& Van Soest 1970) can give good repeatability. Analysis of diverse forage
Figure 1 Relationships between lignin, neutral detergent fibre (NDF) concentration, estimated organic matter digestibility ( $\%$ OMD) of maturing perennial ryegrass. A; $O M D$ and lignin concentration in the dry matter (DM) $\left(r^{2}=0.90\right)$. B; NDF and lignin concentration $\left(r^{2}=0.72\right)$. C; In sacco DM disappearance of ryegrass harvested at three maturation ages $(P>0.05)$.
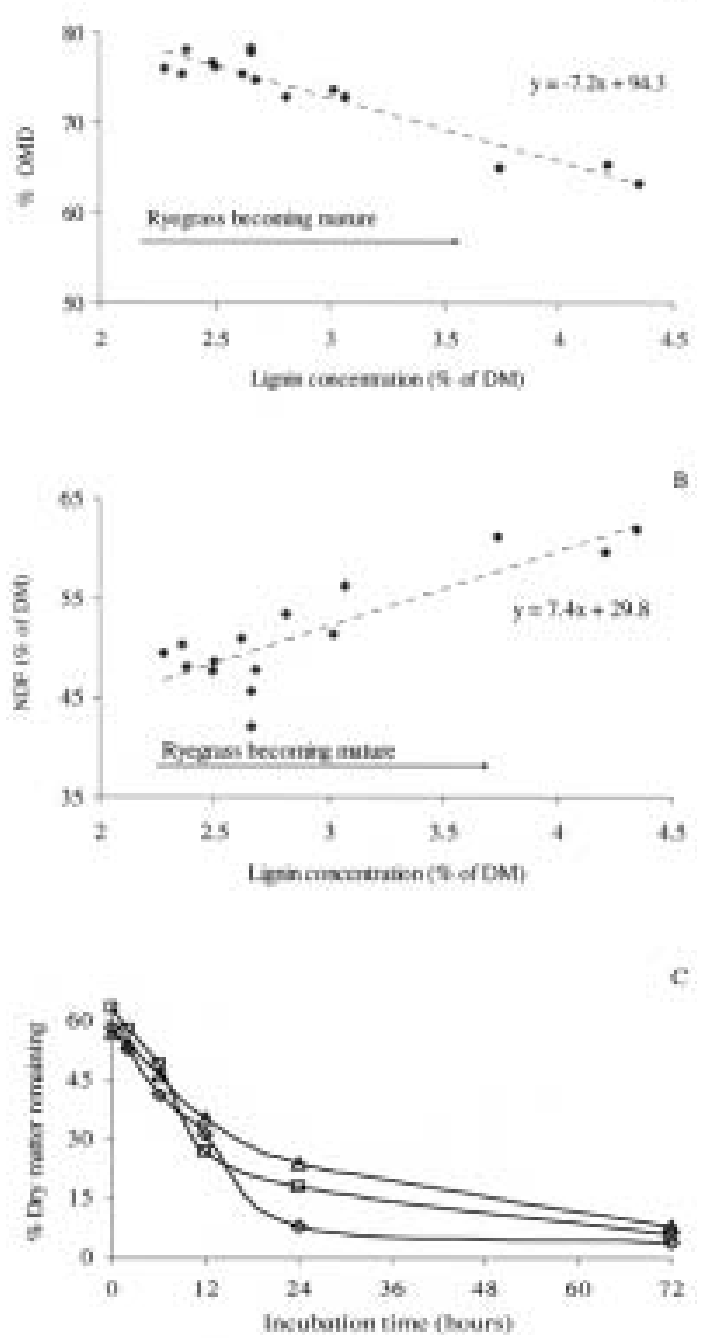

samples confirms the generally lower values in grasses than legumes, show higher values when ensiled, and slow increases in concentration with ryegrass maturation.

Although the increases in lignin and NDF concentration in ryegrass correspond to slower in sacco degradation (Burke et al. 2000; Chaves et al. 2001), there was no increase in lignin concentration for the first 53 days of regrowth (Table 2) when most grazing would take place. This suggests that either structural changes in the non lignin fibre components were responsible for 
slower degradation or that cross linkages between lignin and hemicellulose were responsible (Figure 2). These changes cannot be detected by analyses of lignin

Figure 2 Lignin-carbohydrate complex showing ferulate crosslinkages.

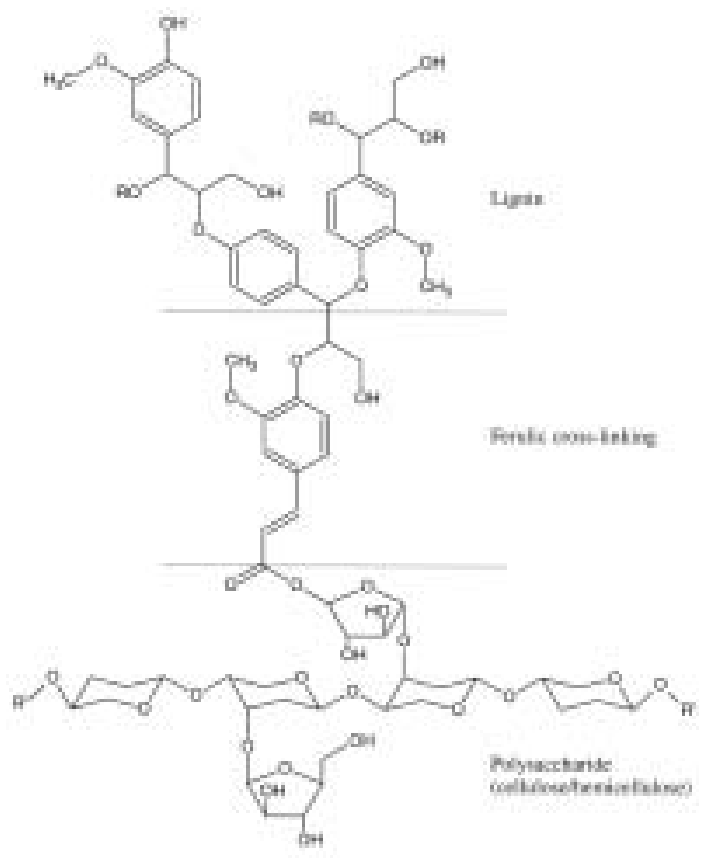

Mlopiod inen Crown (19esa

concentration. Lignin concentration is not the sole determinant of fibre degradation rate of ryegrass (Inoue et al. 1989) and the linkages with fibre constituents (Ralph et al. 1995; Wilson \& Hatfield 1997) have a major impact on fibre degradation. Other factors affecting fibre degradation include the extent of chewing (Waghorn 2002), diet composition, especially inclusion of readily fermentable substrates, level of feeding and rumen $\mathrm{pH}$. Future improvements in the nutritive value of ryegrass must also reduce the extent or effectiveness of cross linkages between lignin, hemicellulose and cellulose in a manner that enable plants to retain their structural integrity. These changes may involve biotechnology and the identification of the brown midrib mutant of corn, with substantial higher digestibility (Barrière et al. 1992), provides an incentive for investigation. Casler (1999) demonstrated that a 20 year plant breeding effort could theoretically result in a new cultivar (for most perennial forage species) with an in vitro digestibility up to $10 \%$ higher than the original population.

The simplified procedure for lignin analysis and future prediction by NIRS (Corson et al. 1999) will improve estimation of feeding value for fresh and ensiled forages.
The principal driver for this procedure was a need for including lignin values in the CNCPS (Cornell dairy nutrition) model to assist in ration formulation for dairy cows.

\section{ACKNOWLEDGEMENTS}

New Zealand Official Development Assistance (NZODA) scholarship for financial support of Alexandre Vieira Chaves.

\section{REFERENCES}

Barrière, Y.; Traineau, R; Emile, J.C.; Hébert, Y. 1992. Variation and covariation of silage maize digestibility estimated from digestion trials with sheep. Euphytica 59: 61-72.

Burke, J.L.; Waghorn, G.C.; Brookes, I.M.; Attwood, G.T. 2000. Formulating total mixed rations from forages - defining the digestion kinetics of contrasting species. Proceedings of the New Zealand Society of Animal Production 60: 9-14.

Casler, M.D. 1999. Breeding for improved forage quality: potentials and problems. Proceedings of the International Grassland Congress VIII: 323-330.

Chaves, A.V.; Waghorn, G.C.; Brookes, I.M.; Burke, J.L. 2001. Digestion kinetics of mature grasses. Proceedings of the New Zealand Society of Animal Production 61: 8-12.

Chaves, A.V.; Waghorn, G.C.; Brookes, I.M.; Hedderley, D. 2002. Digestion kinetics of ryegrass. Proceedings of the New Zealand Society of Animal Production 62: 157-162.

Chesson, A. 1988. Lignin-polysaccharide complexes of the plant cell wall and their effect on microbial degradation in the rumen. Animal Feed Science and Technology 21: 219-228.

Corson, D.C.; Waghorn, G.C.; Ulyatt, M.J.; Lee, J. 1999. NIRS: Forage analysis and livestock feeding. Proceedings of the New Zealand Grassland Association 61: 127-132.

Goering, H.K.; Van Soest, P.J. 1970. Forage fiber analyses (apparatus, reagents, procedures, and some applications). Agriculture handbook no. 379, Agriculture Research Service USDA, Washington (DC), USA. 20 pp.

Hatfield, R.D.; Jung, H.J.G.; Ralph, J.; Buxton, D.R.; Weimer, P.J. 1994. A comparison of the insoluble residues produced by klason lignin and acid detergent lignin procedures. Journal Science Food Agriculture 65:51-58.

Hatfield, R.D.; Ralph, J.; Grabber, J. 1999. Cell wall structural foundations: molecular basis for improving forage digestibilities. Crop Science 39:27-37.

Inoue, T.; Brookes, I.M.; Barry, T. 1989. Effects of selection for shear strength on the voluntary intake 
and digestion of perennial ryegrass fed to sheep. Proceedings of the New Zealand Society of Animal Production 49: 221-224.

Jung, H.G.; Fahey, G.C. 1983. Nutritional implications of phenolic monomers and lignin: a review. Journal of Animal Science 57: 206-219.

Jung, H.G.; Mertens, D.R.; Payne, A.J. 1997. Correlation of acid detergent lignin and klason lignin with digestibility of forage dry matter and neutral detergent fiber. Journal of Dairy Science 80: 1622-1628.

Mertens, D.R. 1992. Critical conditions in determining detergent fibers. pp. c1-c8. In: Proceedings of National Forage Testing Association (NFTA) Forage Analysis Workshop, September 16-17, Denver (CO), USA.

Ralph, J.; Grabber, J.H.; Hatfield, R.D. 1995. Ligninferulate cross-links in grasses: active incorporation of ferulate polysaccharide esters into ryegrass lignins. Carbohydrates Research 275: 167-178.

Van Soest, P.J. 1967. Development of a comprehensive system of feed analyses and its application to forages. Journal of Animal Science 26: 119-128.

Van Soest, P.J. 1978. Preharvest factors influencing quality of conserved forage. Journal of Animal Science 47: 712-720.

Waghorn, G. 2002. Can forages match concentrate diets for dairy production? Proceedings of the New Zealand Society of Animal Production 62: 261-266.

Wilson, J.R.; Hatfield, R.D. 1997. Structural and chemical changes of cell wall types during stem development: consequences for fibre degradation by rumen microflora. Australian Journal of Agricultural Research 48: 165-180. 